\title{
Synthesis of Pegylated Manganese Protoporphyrin as a Catalase Mimic and Its Therapeutic Application to Acetaminophen-Induced Acute Liver Failure
}

\author{
Tianli Zhang, ${ }^{a}$ Jun Fang, ${ }^{b}$ Hiroyasu Tsutsuki, ${ }^{a}$ Katsuhiko Ono, ${ }^{a}$ Waliul Islam, ${ }^{a}$ and \\ Tomohiro Sawa*,a \\ ${ }^{a}$ Department of Microbiology, Graduate School of Medical Sciences, Kumamoto University; 1-1-1 Honjo, Chuo-ku, \\ Kumamoto 860-8556, Japan: and ${ }^{b}$ Laboratory of Microbiology and Oncology, Faculty of Pharmaceutical Sciences, \\ Sojo University; 4-22-1 Ikeda, Nishi-ku, Kumamoto 860-0082, Japan. \\ Received February 15, 2019; accepted April 10, 2019
}

\begin{abstract}
Metalloporphyrin derivatives have been investigated for their therapeutic potential for oxidative stressrelated diseases because of their scavenging of reactive oxygen species (ROS). Here, we describe the synthesis, physicochemical properties, and ROS-scavenging activities of one such derivative-polyethylene glycol (PEG)-conjugated manganese protoporphyrin (PEG-MnPP). Carboxyl groups of the protoporphyrin ring at the $\mathrm{C} 6$ and $\mathrm{C} 7$ positions were first conjugated with ethylenediamine to introduce amino groups into the protoporphyrin structure. The amino groups were then reacted with succinimidyl PEG, with an average molecular weight of 2000, to obtain pegylated protoporphyrin (PEG-PP). Manganese was chelated to the protoporphyrin ring by incubating PEG-PP and manganese acetate in methanol. Dynamic light scattering and fluorescent spectrometry analyses revealed that PEG-MnPP self-assembled into nanoparticles in aqueous media with an apparent diameter of $70 \mathrm{~nm}$. PEG-MnPP effectively eliminated hydrogen peroxide from cell culture media and protected cultured mammalian cells from toxic insults induced by hydrogen peroxide exposure or by 6-hydroxydopamine treatment. Intravenous administration of PEG-MnPP to mice significantly suppressed acute liver failure that had been induced by acetaminophen overdose. These data warrant additional investigation to study the therapeutic potential of PEG-MnPP as a water-soluble metalloporphyrinbased catalase mimic for oxidative stress-associated diseases.
\end{abstract}

Key words pegylated manganese protoporphyrin; reactive oxygen species; oxidative stress; antioxidant; acute liver failure; acetaminophen

\section{INTRODUCTION}

In aerobic organisms, reactive oxygen species (ROS) form under various conditions such as aerobic respiration in mitochondria and immune cell activation during inflammation. ${ }^{1-3)}$ Because of the toxic nature of ROS, aerobic organisms possess extremely potent antioxidant mechanisms, including lowmolecular-weight antioxidants such as glutathione and ROSscavenging enzymes such as superoxide dismutase (SOD) and catalase, to remove these ROS. ${ }^{4,5)}$ However, if an imbalance occurs between ROS and the antioxidant mechanisms, ROS accumulate and cause tissue damage, which leads to oxidative stress and associated diseases. ${ }^{6,7)}$

Metalloporphyrins comprise a class of synthetic catalytic antioxidants that mimic the body's own antioxidant enzymes such as SOD and catalase and can detoxify a wide range of ROS, including superoxide $\left(\mathrm{O}_{2}^{-}\right)$and hydrogen peroxide $\left(\mathrm{H}_{2} \mathrm{O}_{2}\right){ }^{8-10}$ Manganese porphyrins have been studied as potent SOD and catalase mimics. ${ }^{11)}$ Examples of antioxidant manganese porphyrins include manganese (III) meso-tetrakis (4-benzoic acid) porphyrin (MnTBAP) and manganese (III) meso-tetrakis( $N$-alkylpyridinium-2-yl)porphyrin. ${ }^{11)}$

We previously reported that the physicochemical and pharmacological properties of metalloporphyrins were dramatically affected by the introduction of amphiphilic polyethylene glycol (PEG) chains into the metalloporphyrin structure. ${ }^{12)}$ For example, zinc protoporphyrin ( $\mathrm{ZnPP})$, a heme oxygenase (HO) inhibitor, became highly water soluble and was effectively delivered to solid tumors via pegylation. ${ }^{12)}$ Enzymological studies suggested that pegylated ZnPP (PEG-ZnPP) could bind to $\mathrm{HO}$ and inhibit the enzyme's activity, as did native $\mathrm{ZnPP} .{ }^{12-14)}$ In this study, we investigated the effects of pegylation on the ROS-scavenging activities of manganese protoporphyrin (MnPP). We first synthesized pegylated MnPP (PEG-MnPP). We then determined the antioxidant activities of PEG-MnPP by means of $\mathrm{O}_{2}^{-}$- and $\mathrm{H}_{2} \mathrm{O}_{2}$-scavenging activities. We also assessed the effects of PEG-MnPP treatment on oxidative stressrelated conditions by using cell culture models and an in vivo acute liver failure model induced by acetaminophen (APAP).

\section{MATERIALS AND METHODS}

Chemicals Protoporphyrin IX (PP) was purchased from Sigma Chemical Co. (St. Louis, MO, U.S.A.). The succinimidyl derivative of PEG (ME-020CS), with an average molecular weight of 2000, was from NOF Co. (Tokyo, Japan). $N$-tert-butoxycarbonyl (Boc)-ethylenediamine was purchased from Tokyo Chemical Industry Co. Ltd. (Tokyo, Japan). Tetrahydrofuran (THF), triethylamine (TEA), ethyl chloroformate, $N, N$-dimethylformamide (DMF), diethyl ether, and trifluoroacetic acid (TFA) were from Wako Pure Chemical Industries, Ltd. (Osaka, Japan). Manganese (II) acetate tetrahydrate was from Nacalai Tesque Inc. (Kyoto, Japan). 6-Hydroxydopamine hydrochloride (6-OHDA, H4381) and 2',7'-dichlorofluorescein 


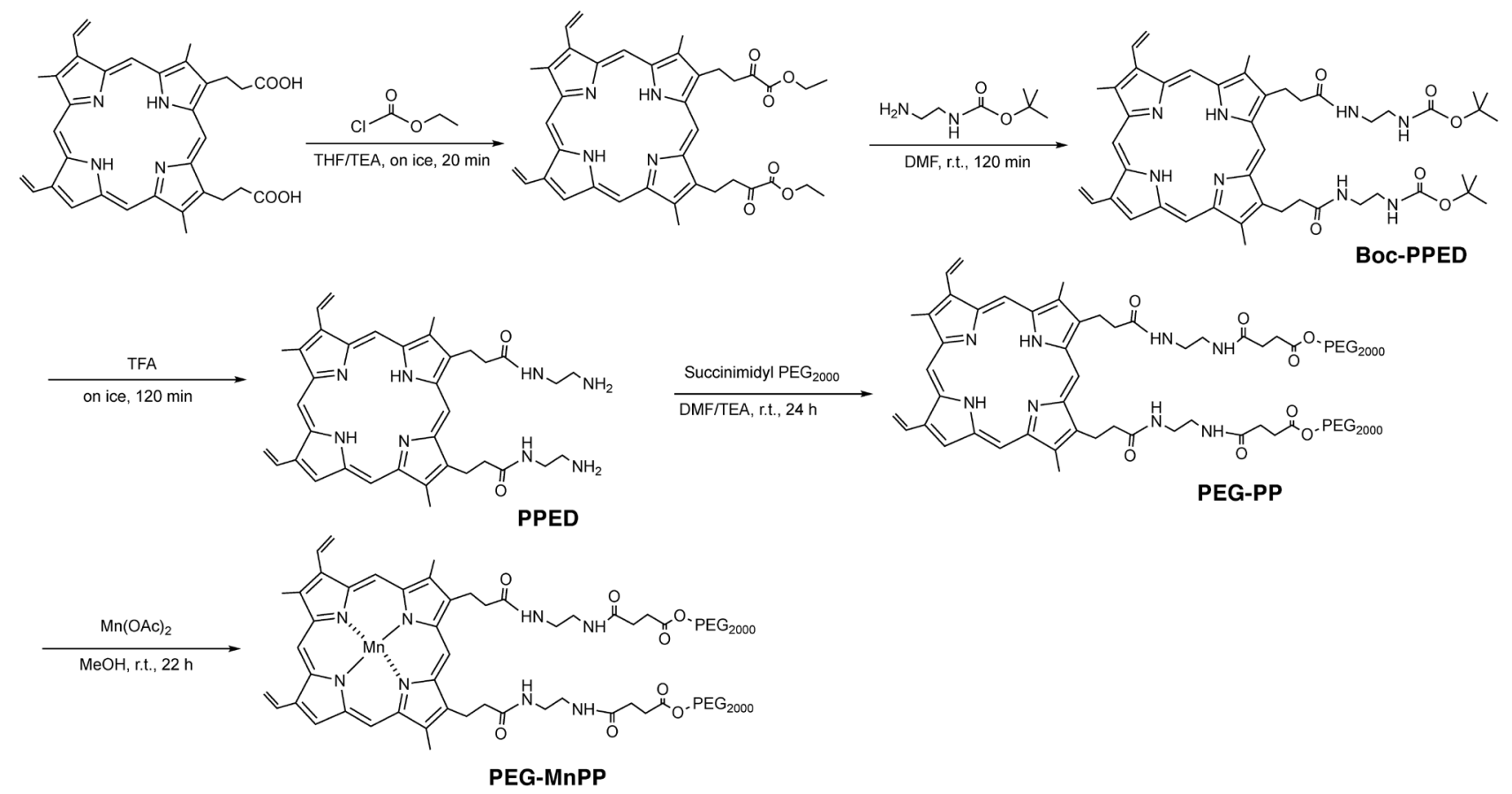

Fig. 1. Synthesis of PEG-MnPP

r.t., room temperature.

diacetate (DCFH-DA, D6883) were purchased from SigmaAldrich (St. Louis, MO, U.S.A.). APAP was from Terumo Corporation (Tokyo, Japan) and from FUJIFILM Wako Pure Chemical Corporation (Osaka, Japan). MnTBAP was obtained from Santa Cruz Biotechnology (Santa Cruz, CA, U.S.A.). MitoSOX ${ }^{\mathrm{TM}}$ Red mitochondrial Superoxide Indicator (M36008) was from Thermo Fisher Scientific (Waltham, MA, U.S.A.).

Synthesis of PEG-MnPP PEG-MnPP was synthesized according to a protocol similar to that reported previously ${ }^{12-14)}$ with some modifications. Figure 1 illustrates the overall scheme, which contains three major steps: (i) introduction of amino groups into the protoporphyrin ring by reacting ethylenediamine with the intrinsic carboxyl groups of the ring; (ii) PEG conjugation to the amino groups; and (iii) chelation of $\mathrm{Mn}^{2+}$ to the PEG-porphyrin ring. Detailed information for each step is presented below.

Synthesis of Bis(ethylenediamino)-Protoporphyrin (PPED) PP (200 mg, $0.36 \mathrm{mmol}$ ) was suspended in $40 \mathrm{~mL}$ of THF and cooled to $0^{\circ} \mathrm{C}$ on ice. With stirring, TEA $(0.5 \mathrm{~mL}, 3.6 \mathrm{mmol})$ was added, followed by drop-wise addition of ethyl chloroformate $(0.68 \mathrm{~mL}, 7.2 \mathrm{mmol})$. The reaction was carried out for $20 \mathrm{~min}$ and continued at room temperature for $15 \mathrm{~min}$. The resultant suspension was filtered to remove the TEA-HCl and was then subjected to evaporation in vacuo to remove THF and ethyl chloroformate, which thereby generated activated PP. Then, $0.25 \mathrm{~mL}$ of Boc-ethylenediamine $(1.6 \mathrm{mmol}, 2.2 \mathrm{M}$ excess to carboxyl groups in PP) was dissolved in $2 \mathrm{~mL}$ of DMF, to which the activated PP (described above), which had been dissolved in $10 \mathrm{~mL}$ of DMF, was added in drop-wise fashion. The reaction was continued at room temperature with stirring for $2 \mathrm{~h}$. The product was then precipitated with $10 \times$ volumes of chilled diethyl ether by using centrifugation $\left(4000 \times \boldsymbol{g}, 5 \mathrm{~min}, 4^{\circ} \mathrm{C}\right)$. The precipitate was washed 3 times with ice-cold diethyl ether, and a solid product (PPED-Boc) was obtained after removing diethyl ether by evaporation.
The purity of PPED-Boc was $99.5 \%$ according to HPLC, as described below. Finally, the Boc group was removed from PPED-Boc by dissolving PPED-Boc in $3 \mathrm{~mL}$ of TFA and keeping it on ice for $2 \mathrm{~h}$. The product (PPED-TFA) was precipitated and washed with diethyl ether as described above to yield $190 \mathrm{mg}$ of product with a purity of $98.9 \%$ as determined by HPLC.

Conjugation of PPED with PEG The PPED-TFA obtained $(190 \mathrm{mg})$, which consisted of about $80 \%$ PPED $(0.23 \mathrm{mmol})$, was dissolved in $20 \mathrm{~mL}$ of DMF. To this solution were added succinimidyl PEG, $2.0 \mathrm{~g}(1 \mathrm{mmol}$, about a $2 \times$ molar excess to the amino groups in PPED), and $95 \mu \mathrm{L}$ of TEA $(0.69 \mathrm{mmol})$. The reaction proceeded at room temperature for $24 \mathrm{~h}$ with stirring. The product was then precipitated with $20 \times$ volumes of chilled diethyl ether by using centrifugation $(4000 \times \boldsymbol{g}$, $5 \mathrm{~min}, 4^{\circ} \mathrm{C}$ ), after which the sample was washed 3 times with ice-cold diethyl ether. Finally, $2.1 \mathrm{~g}$ of PEG-conjugated PP (PEG-PP) was obtained with a purity of $97.6 \%$, as determined with HPLC. The PP content (loading) was quantified as $7.6 \%$, on the basis of an analysis with UV absorption at $406 \mathrm{~nm}$ and using a standard curve for free PP in dimethyl sulfoxide (DMSO) as a reference.

Chelation of Manganese to PEG-PP PEG-PP (745 mg, $0.1 \mathrm{mmol}$ porphyrin equivalent) was dissolved in $75 \mathrm{~mL}$ of methanol, to which $2.89 \mathrm{~g}(10.8 \mathrm{mmol})$ of manganese (II) acetate tetrahydrate was added. The solution was stirred at room temperature for $22 \mathrm{~h}$ to complete the chelation of $\mathrm{Mn}^{2+}$ to the porphyrin ring. After the reaction, methanol was removed by evaporation to yield the crude PEG-MnPP. PEG-MnPP was then purified by precipitating unreacted manganese (II) acetate tetrahydrate with chloroform and then washing 3 times with chloroform. The final product, after evaporation of chloroform, was dissolved in $100 \mathrm{~mL}$ of deionized water followed by lyophilization. The yield of PEG-MnPP after lyophilization was $645 \mathrm{mg}$.

HPLC The formation and purity of products were 
confirmed by using the LC-2000Plus series HPLC system (JASCO, Tokyo, Japan) equipped with a PU-2080 pump, UV-2075 UV/Visible detector (integrator output scale was $1 \mathrm{~V} / 1.0 \mathrm{AU})$, and 807-IT integrator. The Asahipak GF-310 HQ column $(7.5 \times 300 \mathrm{~mm})$ (Showa Denko, Tokyo, Japan) was used. The mobile phase consisted of $70 \%$ methanol, $30 \%$ DMSO, and $0.001 \%$ TFA at a flow rate of $0.8 \mathrm{~mL} / \mathrm{min}$; eluate was monitored at $415 \mathrm{~nm}$ for PP and at $470 \mathrm{~nm}$ for MnPP.

Dynamic Light Scattering PEG-MnPP was dissolved in deionized water at $7 \mathrm{mg} / \mathrm{mL}$ and filtered through a $0.45-\mu \mathrm{m}$ filter. Particle size was measured by using dynamic light scattering (ELS-Z2; Photal Otsuka Electronics, Osaka, Japan) and was calculated by using the cumulant and histogram methods.

$\mathrm{O}_{2}^{-}$Decomposition Assay SOD activity was measured by means of the SOD Assay Kit-WST (Dojindo Laboratories, Kumamoto, Japan) according to the manufacturer's instructions. This assay is based on the reduction of WST-1 by $\mathrm{O}_{2}^{-}$to formazan. In brief, $200 \mu \mathrm{L}$ of WST working solution was added to $20 \mu \mathrm{L}$ of PEG-MnPP $(100 \mu \mathrm{M})$ or MnTBAP $(100 \mu \mathrm{M})$; the samples were mixed by pipetting them into a 96-well plate, after which the samples were mixed with $20 \mu \mathrm{L}$ of enzyme working solution. After incubation for $20 \mathrm{~min}$ at $37^{\circ} \mathrm{C}$, absorbance was measured at $490 \mathrm{~nm}$ via a microplate reader (Bio-Rad, Hercules, CA, U.S.A.). The rate of WST-1 reduction was calculated by using an SOD standard curve as described in the manufacturer's instructions.

$\mathbf{H}_{2} \mathrm{O}_{2}$ Decomposition Assay To determine the $\mathrm{H}_{2} \mathrm{O}_{2}$ decomposition activity of test compounds, $50 \mu \mathrm{M}$ solutions of the test compounds prepared in Dulbecco's Modified Eagle's Medium (DMEM; Wako Pure Chemical Industries, Ltd.) and supplemented with $10 \%$ heat-inactivated fetal bovine serum were reacted with $2 \mathrm{mM} \mathrm{H}_{2} \mathrm{O}_{2}$, as described in the figure legends. After the reaction, $\mathrm{H}_{2} \mathrm{O}_{2}$ decomposition was evaluated by means of the Hydrogen Peroxide Colorimetric Detection Kit (Enzo Sciences, Plymouth Meeting, PA, U.S.A.) according to the manufacturer's protocol. In brief, $2-\mu \mathrm{L}$ samples of the reaction mixtures were added to $18 \mu \mathrm{L}$ of water, and the diluted samples were pipetted into blank wells, to which was added $40 \mu \mathrm{L}$ of detection reagent. After incubation for $15 \mathrm{~min}$ at $37^{\circ} \mathrm{C}$, absorbance was measured at $595 \mathrm{~nm}$ with a microplate reader (Bio-Rad).

Cell Lines and Culture Conditions HeLa cells, the human cervical cancer cell line, were cultured in Eagle's Minimum Essential Medium (Wako Pure Chemical Industries, Ltd.) supplemented with $10 \%$ heat-inactivated fetal bovine serum (MP Biomedicals, Santa Ana, CA, U.S.A.) and 1\% penicillin-streptomycin (Nacalai Tesque). SH-SY5Y cells, the human neuroblastoma cell line, and human hepatocellular carcinoma cell line, HuH-7 cells were cultured in DMEM supplemented with $10 \%$ heat-inactivated fetal bovine serum and $1 \%$ penicillin-streptomycin. THP-1 cells were cultured in RPMI 1640 medium supplemented with $10 \%$ heat-inactivated fetal bovine serum and $1 \%$ penicillin-streptomycin. All cells were cultured in a $5 \% \mathrm{CO}_{2}$ humidified incubator at $37^{\circ} \mathrm{C}$.

Cell Treatment Cell viability was determined by using two different methods-the 3-(4,5-dimethylthiazol-2-yl)-2,5diphenyltetrazolium bromide (MTT) assay (Dojindo Laboratories) or the trypan blue exclusion assay (Automated Cell Counter Countess, Invitrogen, Eugene, OR, U.S.A.) depending on the cell type. For adhesive cells such as HeLa and $\mathrm{SH}$ SY5Y cells, the MTT assay was used. For floating cells such as THP-1 cells, the trypan blue exclusion assay was utilized. In our first experiments, we determined the cytotoxicity of PEG-MnPP and related substances. HeLa cells or THP-1 cells were seeded in a 96-well plate at a density of $1 \times 10^{4}$ cells/ well. After overnight incubation, cells were treated with PEGMnPP, PEG-PP, or MnTBAP for $24 \mathrm{~h}$ or cells were untreated. Cell viability was then determined via the MTT assay and the trypan blue exclusion assay for HeLa cells and THP-1 cells, respectively, according to the manufacturer's instructions.

We determined the effects of PEG-MnPP on ROS-induced cell death by using two different models. HeLa cells were seeded in a 96-well plate at a density of $1 \times 10^{4}$ cells per well and were cultured overnight. Cells were then exposed to $1 \mathrm{mM} \mathrm{H}_{2} \mathrm{O}_{2}$ in the absence or the presence of additives such as PEG-MnPP for $5 \mathrm{~h}$. SH-SY5Y cells were seeded in a 96-well plate at a density of $5 \times 10^{4}$ cells per well and were cultured for $8 \mathrm{~h}$. Cells were treated with 6-OHDA at specific concentrations $(12.5-100 \mu \mathrm{M})$ in the absence or presence of $30 \mu \mathrm{M}$ PEG-MnPP for $24 \mathrm{~h}$. Cell viability after each treatment was determined by means of the MTT assay.

Measurement of Intracellular ROS Production SHSY5Y cells were seeded in a 96-well plate at a density of $5 \times 10^{4}$ cells per well and were treated with 6-OHDA at indicated concentrations $(12.5-50 \mu \mathrm{M})$ in the absence or presence of $30 \mu \mathrm{M}$ PEG-MnPP or PEG-PP. After incubation for $3 \mathrm{~h}$, cells were rinsed and then loaded with $5 \mu \mathrm{M}$ DCFHDA (Sigma-Aldrich) in Modified Krebs-Ringer solution $\left(44 \mathrm{mM} \mathrm{NaHCO}, 0.9 \mathrm{mM} \mathrm{NaH} \mathrm{PO}_{4}, 110 \mathrm{mM} \mathrm{NaCl}, 5 \mathrm{mM}\right.$ $\mathrm{KCl}, 0.8 \mathrm{mM} \mathrm{MgSO}_{4}, 10 \mathrm{mM}$ glucose, $2 \mathrm{mM} \mathrm{CaCl}_{2}, \mathrm{pH} 7.4$ ) for $15 \mathrm{~min}$. HuH-7 cells were seeded in a 96 -well plate at a density of $1 \times 10^{4}$ cells per well and were treated with APAP at indicated concentrations $(0.2-20 \mathrm{mM})$ in the absence or presence of $30 \mu \mathrm{M}$ PEG-MnPP or PEG-PP. After incubation for $24 \mathrm{~h}$, cells were rinsed and then loaded with $5 \mu \mathrm{M}$ MitoSOX ${ }^{\mathrm{TM}}$ Red mitochondrial Superoxide Indicator (M36008, Thermo Fisher Scientific) for $15 \mathrm{~min}$. Fluorescent images were observed by means of a fluorescence microscope (BZ-X700, Keyence, Osaka, Japan). Three wells for each treatment were analyzed and the relative fluorescent intensity was expressed as a quantitative data.

Animals and Experimental Protocols Male ICR mice (6-8 weeks old) were purchased from Kyudo Co. (Saga, Japan). The animals were allowed free access to food and water at all times and were maintained on a 12-h light/dark cycle in an environment of controlled temperature $\left(20-25^{\circ} \mathrm{C}\right)$ and humidity $(50 \pm 5 \%)$ for 1 week before use. All animal experiments were carried out according to the Guidelines of the Laboratory Protocol of Animal Handling, Sojo University and Kumamoto University.

ICR mice were fasted overnight, after which liver injury was induced via intraperitoneal (i.p.) injections of APAP $(300 \mathrm{mg} / \mathrm{kg}){ }^{15)}$ In the group receiving the PEG-PP or PEGMnPP treatment, mice received one intravenous injection of PEG-PP or PEG-MnPP ( $0.5 \mathrm{mg}$ PP or MnPP equivalent $/ \mathrm{kg}$ dissolved in physiological saline, $0.1 \mathrm{~mL}$ ) via the tail vein at $2 \mathrm{~h}$ after APAP administration. In the control group, mice were injected intravenously with physiological saline. Mice were killed at $24 \mathrm{~h}$ after the APAP injection. The body weights and liver weights were measured, and serum samples were collected for measurement of alanine aminotransferase (ALT).

Statistical Analyses All data are expressed as 


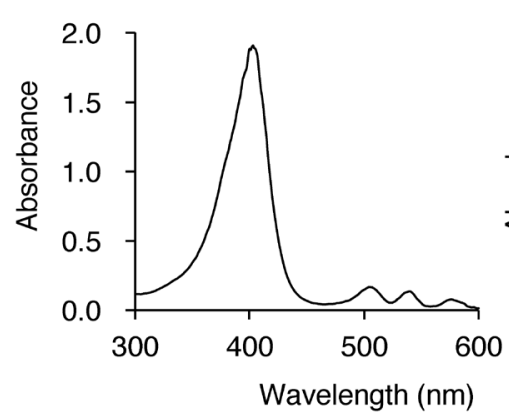

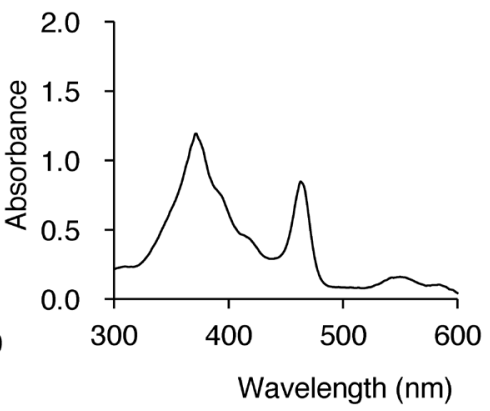

Fig. 2. UV-VIS Spectra of PEG-PP (a) and PEG-MnPP (b) Measured at $2 \mu \mathrm{M}$ in Methanol at r.t.
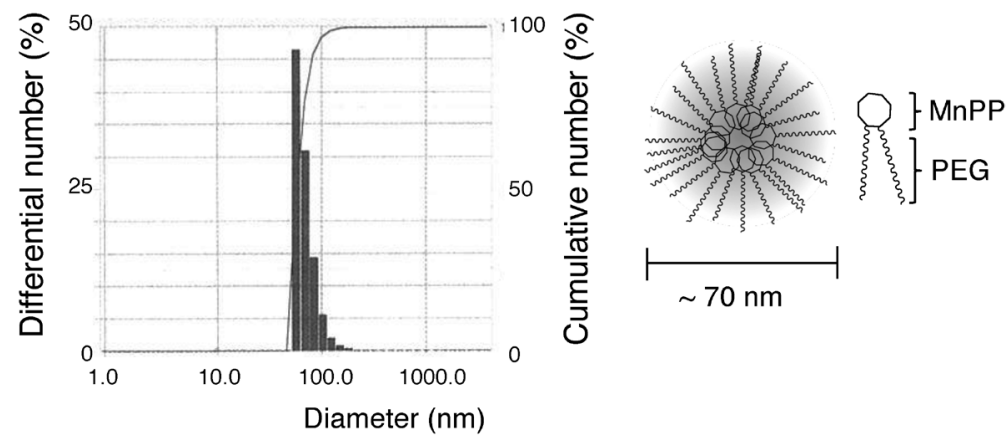

Fig. 3. Dynamic Light Scattering Analysis of PEG-MnPP in Deionized Water
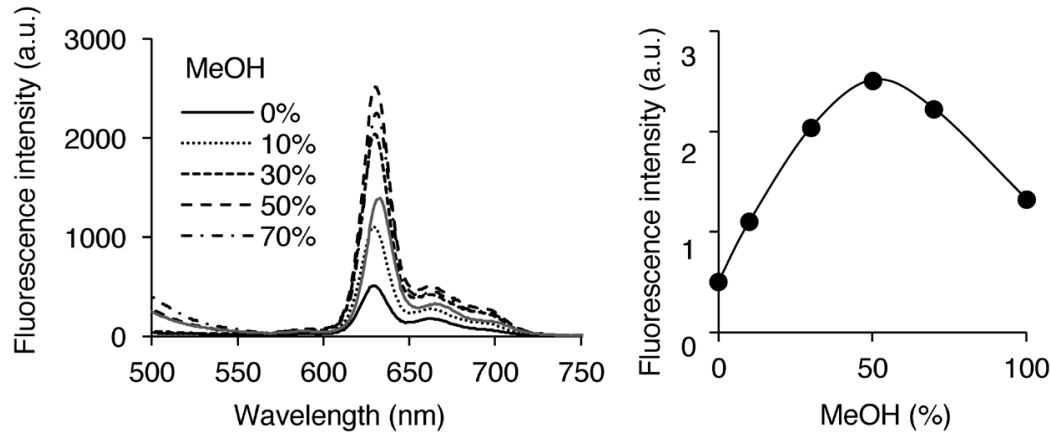

Fig. 4. Fluorescence Spectra of PEG-MnPP in Deionized Water Containing Different Concentrations of Methanol (MeOH)

The left panel shows emission spectra of PEG-MnPP with excitation at $400 \mathrm{~nm}$. The right panel shows the change in fluorescence intensity at $630 \mathrm{~nm}$ with excitation at $400 \mathrm{~nm}$.

means \pm standard deviation (S.D.) Data for each experiment were obtained from at least three independent experiments. Statistical analyses were performed by using Student's $t$-test, with the level of significance set at $p<0.05$.

\section{RESULTS AND DISCUSSION}

Synthesis of PEG-MnPP As Fig. 1 shows, PEG-MnPP was synthesized by incorporating manganese into the PEG-PP structure. Chelation of manganese was carried out by incubating PEG-PP and manganese acetate in methanol, with success of the chelation confirmed by the appearance of the characteristic UV/VIS absorption spectrum for manganese porphyrin (Fig. 2). In fact, PEG-MnPP in methanol has a distinctive split Soret band, which is characteristic for manganese porphyrins, ${ }^{16)}$ with one component appearing at $377 \mathrm{~nm}$ and a weaker one appearing at $466 \mathrm{~nm}$ (Fig. 2(b)). The purity of PEG-MnPP was determined to be higher than $98 \%$ by means of HPLC.

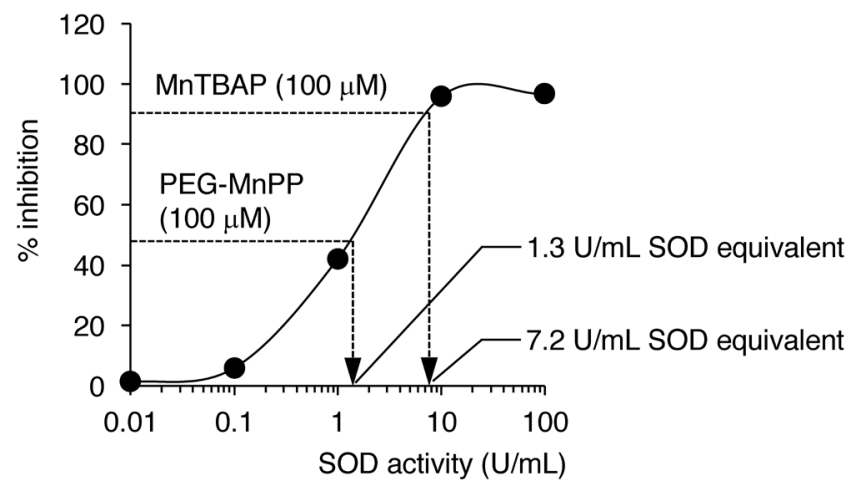

Fig. 5. $\mathrm{O}_{2}^{-}$Decomposition Activity of PEG-MnPP

Calibration curve for SOD-dependent inhibition of WST-1 reduction. Inhibition of WST-1 reduction by $100 \mu \mathrm{M}$ PEG-MnPP and MnTBAP was plotted to determine their SOD equivalent activities. 

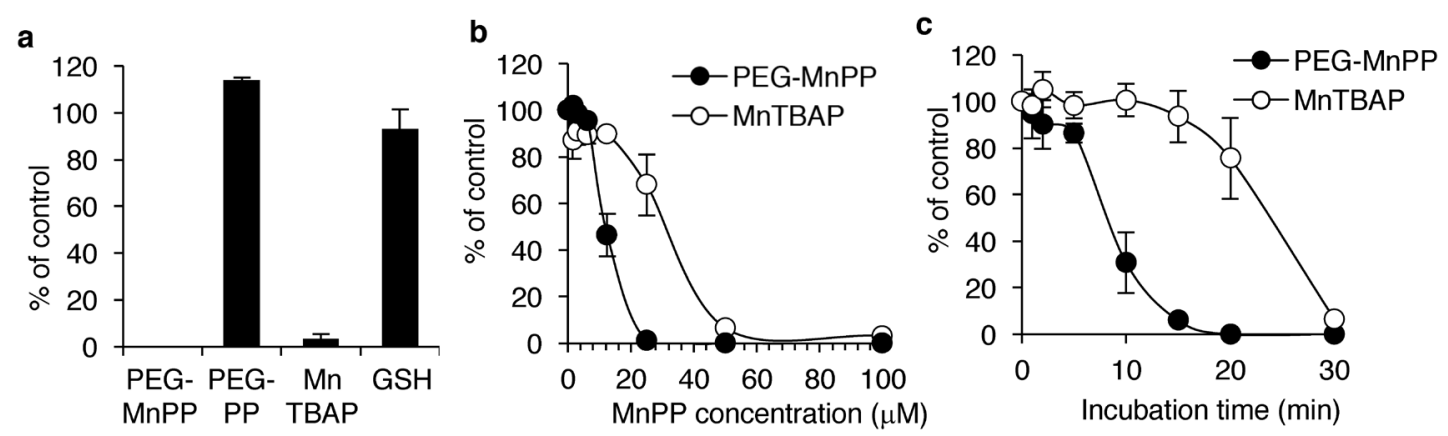

Fig. 6. $\mathrm{H}_{2} \mathrm{O}_{2}$ Decomposition Activity of PEG-MnPP

(a) Specificity. $\mathrm{H}_{2} \mathrm{O}_{2}(2 \mathrm{mM})$ and the indicated compounds $(0.05 \mathrm{mM})$ were incubated together for $30 \mathrm{~min}$. GSH, glutathione. (b) Dose dependence. $\mathrm{H}_{2} \mathrm{O}_{2}$ ( $\left.2 \mathrm{mM}\right)$ was incubated with the indicated concentrations of MnTBAP or PEG-MnPP for $30 \mathrm{~min}$. (c) Time dependence. $\mathrm{H}_{2} \mathrm{O}_{2}(2 \mathrm{mM})$ was incubated with $0.05 \mathrm{mM}$ MnTBAP or PEG-MnPP for the indicated time periods. The amount of $\mathrm{H}_{2} \mathrm{O}_{2}$ that remained in the reaction mixture was determined via a colorimetric assay.

Physicochemical Properties of PEG-MnPP Conjugation of PEG chains to manganese porphyrin greatly increased water solubility of PEG-MnPP. For instance, PEG-MnPP could be dissolved in neutral aqueous buffer at a concentration of approximately $30 \mathrm{mM}$ without heating. We previously found that PEG-ZnPP formed micelle-like molecular assemblies in aqueous media, with a hydrophobic core consisting of ZnPP moieties surrounded by hydrophilic PEG chains. ${ }^{11-13)}$ In this study, we investigated whether PEG-MnPP formed similar molecular assemblies in water. Dynamic light scattering analysis suggested that PEG-MnPP formed nanoparticles having an average diameter of $73.5 \pm 17.9 \mathrm{~nm}$ in water (Fig. 3). Porphyrins are known to exhibit intense fluorescence when they are well dispersed in solution, whereas after aggregation the fluorescence is strongly quenched. ${ }^{17)}$ As Fig. 4 shows, the fluorescence intensity of PEG-MnPP was smaller in water than in methanol and was increased by increasing the methanol content. These data suggest that PEG-MnPP forms micelle-like molecular assemblies in aqueous media.

ROS-Scavenging Activities of PEG-MnPP MnPP derivatives reportedly mimic both SOD and catalase activities. ${ }^{9}$ We first investigated the SOD mimic activity of PEG-MnPP. MnTBAP is one of a class of manganese porphyrins and mimics both SOD and catalase activities. ${ }^{18)} \mathrm{We}$ thus compared MnTBAP with PEG-MnPP. As Fig. 5 illustrates, PEG-MnPP did demonstrate SOD mimic activity but its activity was 5.5 times weaker than that of MnTBAP.

We next studied whether PEG-MnPP could exhibit catalase mimic activity. Figure 6(a) clearly shows that a catalytic concentration $(50 \mu \mathrm{M})$ of PEG-MnPP completely decomposed excess $\mathrm{H}_{2} \mathrm{O}_{2}(2 \mathrm{mM})$ in aqueous media. Metal-free PEG-PP failed to decompose $\mathrm{H}_{2} \mathrm{O}_{2}$. Glutathione (GSH) is a peptidyl antioxidant that is involved in the elimination of $\mathrm{H}_{2} \mathrm{O}_{2}$ in cells. Because glutathione can eliminate $\mathrm{H}_{2} \mathrm{O}_{2}$ by reacting directly with $\mathrm{H}_{2} \mathrm{O}_{2}$, only a marginal decrease in $\mathrm{H}_{2} \mathrm{O}_{2}$ was observed for it under current conditions (Fig. 6(a)). It is interesting that the potency of PEG-MnPP as a catalase mimic was higher than that of MnTBAP. During $30 \mathrm{~min}$ of incubation, PEG-MnPP at $25 \mu \mathrm{M}$ completely decomposed $2 \mathrm{mM} \mathrm{H}_{2} \mathrm{O}_{2}$, whereas MnTBAP required a concentration higher than $50 \mu \mathrm{M}$ for complete decomposition of $\mathrm{H}_{2} \mathrm{O}_{2}$ (Fig. 6(b)). PEG-MnPP also decomposed $\mathrm{H}_{2} \mathrm{O}_{2}$ more rapidly than did MnTBAP (Fig. 6(c)). These data suggest that PEG-MnPP is a potent catalase mimic.

Cytoprotective Effects of PEG-MnPP against ROSMediated Cell Death We first investigated the cytotoxic-
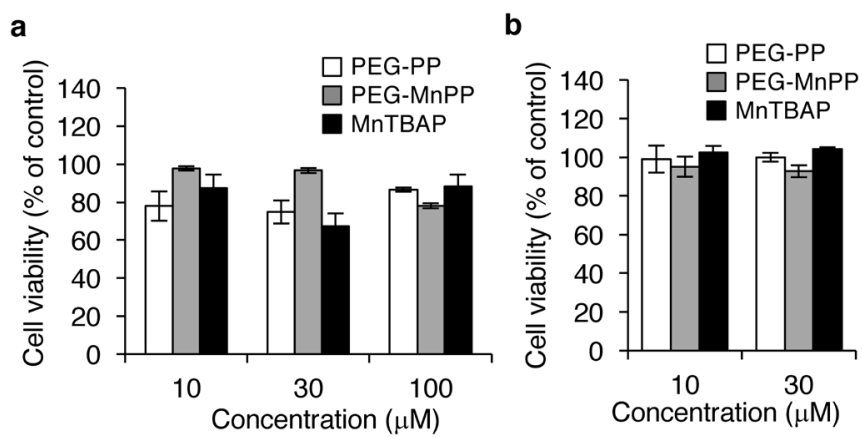

Fig. 7. Effects of PEG-MnPP, PEG-PP, and MnTBAP on Cell Viability

HeLa cells (a) and THP-1 cells (b) were treated with the indicated concentrations of PEG-PP, PEG-MnPP, or MnTBAP for $24 \mathrm{~h}$. Cell viability was then determined by means of the MTT assay (HeLa cells) or the trypan blue exclusion assay (THP-1 cells). Data are means \pm S.D. $(n=3)$.

ity of PEG-MnPP alone to human cell lines to determine the biocompatibility of PEG-MnPP with cells. As seen in Fig. 7, PEG-MnPP treatment did not affect the viability of the epithelial cell line (HeLa cells) as well as the monocyte cell line (THP-1 cells) under the present experimental conditions. We observed no morphological changes of cells treated with PEGMnPP under these conditions (data not shown).

We then studied whether PEG-MnPP could protect cells from oxidative stress-associated cell death. Treatment of $\mathrm{HeLa}$ cells with authentic $\mathrm{H}_{2} \mathrm{O}_{2}$ at concentrations higher than $0.125 \mathrm{mM}$ reduced cell viability to approximately $20 \%$ of untreated controls (Fig. 8(a)). Addition of PEG-MnPP resulted in a marked increase in cell viability, whereas PEG-PP did not show such a cytoprotective effect (Fig. 8(b)). Consistent with $\mathrm{H}_{2} \mathrm{O}_{2}$ removal activities determined in vitro (Fig. 6), the cytoprotective effect of PEG-MnPP was greater than that of MnTBAP (Fig. 8(b)). We next examined the cytoprotective effect of PEG-MnPP in a more biologically relevant model. 6-OHDA is a dopaminergic neurotoxin that can cause neuronal cell death. ${ }^{19)}$ 6-OHDA-induced cell death was reportedly mediated via extracellular auto-oxidation of 6-OHDA to form $\mathrm{H}_{2} \mathrm{O}_{2} \cdot{ }^{20)}$ Consistent with previous report, ${ }^{21)}$ 6-OHDA treatment significantly increased intracellular ROS levels as indicated by the marked increase of fluorescent intensity derived from ROS sensitive probe DCFH-DA (Supplementary Fig. S1 (a,b)). Co-treatment with PEG-PP did not affect ROS production induced by 6-OHDA treatment, whereas PEG-MnPP treatment significantly reduced ROS production in cells (Fig. 8(c), 
a

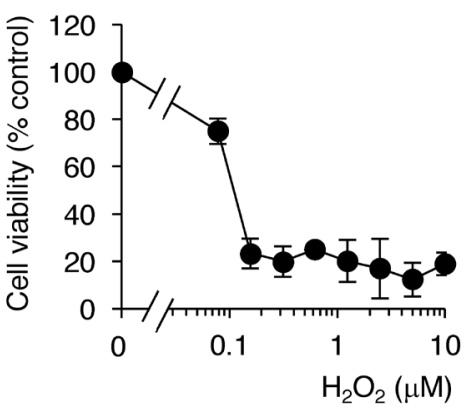

C

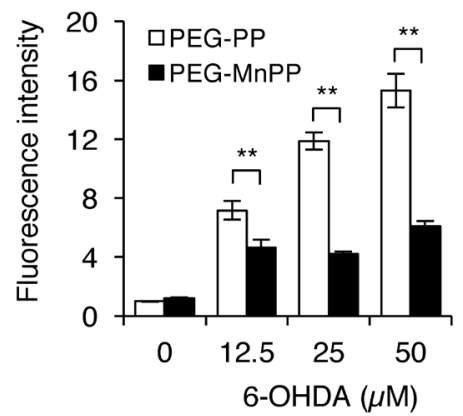

b

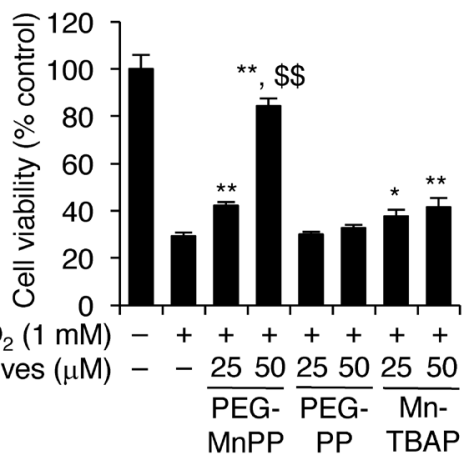

d

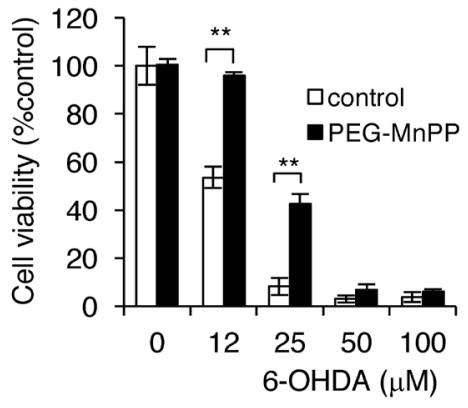

Fig. 8. Cytoprotective Effects of PEG-MnPP against ROS-Mediated Cell Death

(a) Dose-dependent death of HeLa cells exposed to the indicated concentrations of $\mathrm{H}_{2} \mathrm{O}_{2}$ for 90 min. (b) Effects of PEG-MnPP or related molecules on $\mathrm{H}_{2} \mathrm{O}_{2}$-induced cell death. HeLa cells were incubated with $1 \mathrm{mM} \mathrm{H}_{2} \mathrm{O}_{2}$ in the presence of the indicated additives for $5 \mathrm{~h}$. $* p<0.05 ; * *<0.01$ versus cells treated with $1 \mathrm{mM} \mathrm{H}_{2} \mathrm{O}_{2}$ in the absence of additives; $\$ \$, p<0.01$ versus cells treated with $1 \mathrm{mM} \mathrm{H} \mathrm{O}_{2}$ in the presence of $50 \mu \mathrm{M}$ MnTBAP. (c) Effects of PEG-MnPP and PEG-PP on 6-OHDA-induced ROS production in SH-SY5Y cells. SH-SY5Y cells were treated with indicated concentrations of 6-OHDA in the presence of $30 \mu \mathrm{M}$ of PEG-PP or PEG-MnPP for $3 \mathrm{~h}$. After treatment, cells were stained with $5 \mu \mathrm{M}$ DCFH-DA, followed by acquiring fluorescent images. Fluorescent images were analyzed and the intensity was expressed as a relative intensity. Data are mean \pm S.D. ( $n=3$ for each group). $* p<0.05, * * p<0.01$. Representative fluorescent images were shown in Supplementary Fig. S1. (d) Effects of PEG-MnPP on 6-OHDA-induced cell death. SH-SY5Y cells were treated with the indicated concentrations of 6-OHDA in the absence or presence of 30 $\mu$ M PEG-MnPP for $24 \mathrm{~h}$. Cell viability was determined by means of the MTT assay.

a

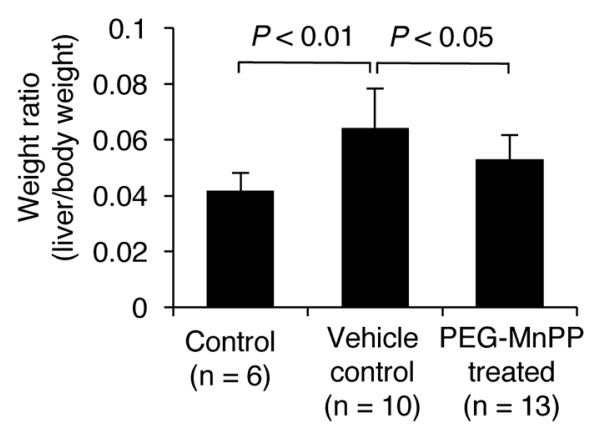

b

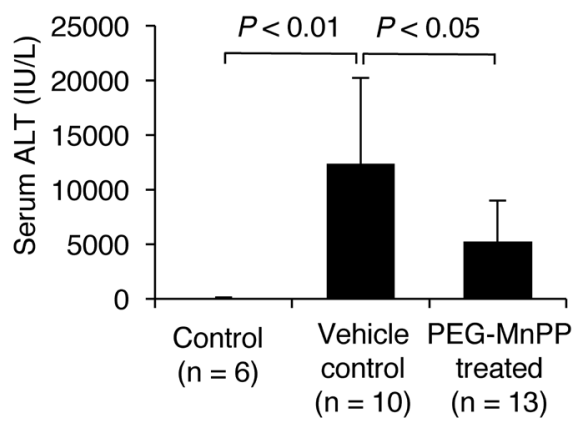

Fig. 9. Therapeutic Effects of PEG-MnPP on APAP-induced Acute Liver Failure

Mice were given APAP intraperitoneally $(300 \mathrm{mg} / \mathrm{kg})$. The treatment group received one injection of PEG-MnPP $(0.5 \mathrm{mg}$ MnPP equivalent $/ \mathrm{kg})$ via the tail vein. After $24 \mathrm{~h}$, mice were killed for the evaluation of liver injury.

Supplementary Fig. S1 (c,d)). In human neuroblastoma SHSY5Y cells, 6-OHDA treatment caused cell death in a dosedependent manner (Fig. 8(d)). PEG-MnPP at $30 \mu \mathrm{M}$ resulted in a marked increase in cell viability, i.e., protection against 6-OHDA-induced cell death (Fig. 8(d)). Under the present conditions, PEG-PP did not have any cytoprotective effects (data not shown). These data clearly indicate that PEG-MnPP effectively eliminated cytotoxic ROS under these cell culture conditions and protected cells from cell death associated with oxidative stress. It should also be noted that although PEGMnPP eliminated ROS in cells treated with $50 \mu \mathrm{M}$ 6-OHDA, cell viability at this dose of 6-OHDA did not recovered by
PEG-MnPP treatment (Fig. 8). This may suggest that, at higher doses of 6-OHDA, ROS independent cell damages may dominate for 6-OHDA-induced cell death.

Therapeutic Effects of PEG-MnPP in APAP-Induced Acute Liver Failure APAP is one of the drugs used most often for its analgesic and antipyretic properties. ${ }^{22,23)}$ At the recommended doses APAP is safe and effective; overdose may result in hepatotoxicity and acute liver failure. ${ }^{22,23)}$ APAP overdose leads to the saturation of the main elimination pathways of APAP in the liver, e.g., the glucuronidation and sulfation pathways; thus, the highly reactive metabolite $N$-acetyl- $p$ benzoquinone imine (NAPQI) accumulates. ${ }^{22,23)}$ NAPQI so 
formed can damage mitochondria in hepatocytes and result in excess production of ROS. ${ }^{22,23)}$ In this study, we examined the therapeutic effects of PEG-MnPP on acute liver failure caused by APAP overdose in a mouse model. Under the current experimental conditions, APAP at $300 \mathrm{mg} / \mathrm{kg}$ induced acute liver failure, as indicated by the marked increase in liver-to-body weight ratio and serum ALT levels (Fig. 9). Administration of PEG-MnPP $(0.5 \mathrm{mg}$ MnPP equivalent $/ \mathrm{kg})$ at $2 \mathrm{~h}$ after the APAP injection significantly reduced both the liver-to-body weight ratio and the serum ALT levels (Fig. 9). On the other hand, treatment with PEG-PP failed to reduce liver damages caused by APAP overdose (Supplementary Fig. S2). As mentioned above, APAP treatment induce mitochondria damages and associated ROS production, ${ }^{24,25)}$ we examined mitochondria-derivaed ROS production by using MitoSOX probe. We found that APAP treatment increased mitochondrial ROS production (Supplementary Fig. S3). Importantly, APAP-induced mitochondrial ROS production was significantly reduced by PEG-MnPP (Supplementary Fig. S3).

Ferret et al. reported the protective effect of MnTBAP against APAP-induced liver failure. ${ }^{26)}$ In their experiments, MnTBAP was administered via the intraperitoneal route at 10 and $20 \mathrm{mg} / \mathrm{kg}$ doses to APAP-treated mice. ${ }^{26)}$ The present study demonstrated that a single injection of PEG-MnPP at a much lower dose was sufficient to produce a therapeutic effect against severe liver damage caused by APAP in vivo.

To our knowledge, this is the first demonstration of potent catalase-like activity of a manganese porphyrin after pegylation. PEG-MnPP behaves as nanoparticles in aqueous media by forming a molecular assembly. As reported for other nanoparticles, ${ }^{27)}$ PEG-MnPP may circulate in vivo for longer time periods because it may escape from renal clearance. At a site of inflammation such as a damaged liver caused by APAP, increased vascular permeability may facilitate leakage of PEG-MnPP and subsequent accumulation in inflamed tissues.

Naruta and Maruyama reported that catalase-like activity of manganese porphyrin could be significantly enhanced when two manganese porphyrin rings were connected by an anthracene linkage to form manganese porphyrin dimers. ${ }^{28)}$ These dimers act synergistically to decompose $\mathrm{H}_{2} \mathrm{O}_{2} \cdot{ }^{28)}$ Kubota et al . developed water-soluble manganese porphyrin dimers that act as a potent catalase mimic, similar to the anthracene-linked manganese porphyrins. ${ }^{8)}$ In the present study, we found that PEG-MnPP more effectively catalyzed decomposition of $\mathrm{H}_{2} \mathrm{O}_{2}$ than did the monomeric MnTBAP (Fig. 6). As just discussed, the manganese porphyrin rings of PEG-MnPP may assemble in aqueous media, which may facilitate intermolecular interactions of manganese porphyrin rings and hence promote $\mathrm{H}_{2} \mathrm{O}_{2}$ decomposition.

The therapeutic potential of manganese porphyrin derivatives has been reported for oxidative stress-associated diseases such as paraquat-induced lung injury and carrageenan-induced lung injury. ${ }^{29)} \mathrm{Li}$ et al. found that the manganese porphyrin derivative HSJ-0017 possesses both SOD and catalase mimic activities; it exerted potent antitumor effects in a tumorbearing mouse model. ${ }^{30}$ ) Additional study is needed to clarify the accumulation in tumors and the antitumor effects of PEGMnPP

In summary, we demonstrated here that PEG-MnPP is a water-soluble and biocompatible synthetic catalase mimic that can effectively eliminate toxic $\mathrm{H}_{2} \mathrm{O}_{2}$. The in vivo mouse model revealed that PEG-MnPP may be able to treat APAP-induced acute liver failure. Continued study is warranted to determine the therapeutic effects of PEG-MnPP on inflammatory disorders that are associated with extensive production of ROS.

Acknowledgments We are grateful to Dr. Takuro Niidome (Kumamoto University) for his valuable comments about our manuscript. We also thank J. B. Gandy for her editing of the manuscript. This study was supported in part by Grants from the Japan Society for the Promotion of Science (JSPS) KAKENHI Numbers 25430162 and 16K08217 to J. Fang, Number 17K10019 to H. Tsutsuki, a Grant from the Takeda Science Foundation to H. Tsutsuki, and the Otsuka Toshimi Scholarship Foundation to T. Zhang.

Conflict of Interest The authors declare no conflict of interest.

Supplementary Materials The online version of this article contains supplementary materials.

\section{REFERENCES}

1) D'Autreaux B, Toledano MB. ROS as signalling molecules: mechanisms that generate specificity in ROS homeostasis. Nat. Rev. Mol. Cell Biol., 8, 813-824 (2007).

2) Sawa $T$, Ihara H, Akaike T. Antioxidant effect of a nitrated cyclic nucleotide functioning as an endogenous electrophile. Curr. Top. Med. Chem., 11, 1854-1860 (2011).

3) Halliwell B. Biochemistry of oxidative stress. Biochem. Soc. Trans., 35, 1147-1150 (2007)

4) Niki E. Assessment of antioxidant capacity in vitro and in vivo. Free Radic. Biol. Med., 49, 503-515 (2010).

5) Johnson F, Giulivi C. Superoxide dismutases and their impact upon human health. Mol. Aspects Med., 26, 340-352 (2005).

6) Halliwell B. Oxidative stress and neurodegeneration: where are we now? J. Neurochem., 97, 1634-1658 (2006).

7) Halliwell B. Oxidative stress and cancer: have we moved forward? Biochem. J., 401, 1-11 (2007).

8) Kubota $\mathrm{R}$, Imamura $\mathrm{S}$, Shimizu $\mathrm{T}$, Asayama S, Kawakami H. Synthesis of water-soluble dinuclear Mn-porphyrin with multiple antioxidative activities. ACS Med. Chem. Lett., 5, 639-643 (2014).

9) Batinic-Haberle I, Tovmasyan A, Spasojevic I. An educational overview of the chemistry, biochemistry and therapeutic aspects of Mn porphyrins-From superoxide dismutation to $\mathrm{H}_{2} \mathrm{O}_{2}$-driven pathways. Redox Biol., 5, 43-65 (2015).

10) Liang LP, Huang J, Fulton R, Pearson-Smith JN, Day BJ, Patel M. Pre-clinical therapeutic development of a series of metalloporphyrins for Parkinson's disease. Toxicol. Appl. Pharmacol., 326, 34-42 (2017).

11) Batinic-Haberle I, Spasojevic I, Tse HM, Tovmasyan A, Rajic Z, St Clair DK, Vujaskovic Z, Dewhirst MW, Piganelli JD. Design of Mn porphyrins for treating oxidative stress injuries and their redoxbased regulation of cellular transcriptional activities. Amino Acids, 42, 95-113 (2012).

12) Sahoo SK, Sawa T, Fang J, Tanaka S, Miyamoto $Y$, Akaike T, Maeda H. Pegylated zinc protoporphyrin: a water-soluble heme oxygenase inhibitor with tumor-targeting capacity. Bioconjug. Chem., 13, 1031-1038 (2002)

13) Fang J, Sawa T, Akaike T, Akuta T, Sahoo SK, Khaled G, Hamada A, Maeda H. In vivo antitumor activity of pegylated zinc protoporphyrin: targeted inhibition of heme oxygenase in solid tumor. Cancer Res., 63, 3567-3574 (2003).

14) Fang J, Sawa $T$, Akaike $T$, Greish $K$, Maeda H. Enhancement of 
chemotherapeutic response of tumor cells by a heme oxygenase inhibitor, pegylated zinc protoporphyrin. Int. J. Cancer, 109, 1-8 (2004).

15) Wang JX, Zhang C, Fu L, Zhang DG, Wang BW, Zhang ZH, Chen $\mathrm{YH}, \mathrm{Lu} \mathrm{Y}, \mathrm{Chen} \mathrm{X}, \mathrm{Xu}$ DX. Protective effect of rosiglitazone against acetaminophen-induced acute liver injury is associated with down-regulation of hepatic NADPH oxidases. Toxicol. Lett., 265 , 38-46 (2017).

16) Batinić-Haberle I, Benov L, Spasojević I, Fridovich I. The ortho effect makes manganese(III) meso-tetrakis $(N$-methylpyridinium2-yl)porphyrin a powerful and potentially useful superoxide dismutase mimic. J. Biol. Chem., 273, 24521-24528 (1998).

17) Nishide H, Mihayashi K, Tsuchida E. Dissociation of aggregated ferroheme complexes and protoporphyrin IX by water-soluble polymers. Biochim. Biophys. Acta, 498, 208-214 (1977).

18) Day BJ, Fridovich I, Crapo JD. Manganic porphyrins possess catalase activity and protect endothelial cells against hydrogen peroxide-mediated injury. Arch. Biochem. Biophys., 347, 256-262 (1997).

19) Soto-Otero R, Mendez-Alvarez E, Hermida-Ameijeiras A, MunozPatino AM, Labandeira-Garcia JL. Autoxidation and neurotoxicity of 6-hydroxydopamine in the presence of some antioxidants: potential implication in relation to the pathogenesis of Parkinson's disease. J. Neurochem., 74, 1605-1612 (2000).

20) Hanrott K, Gudmunsen L, O’Neill MJ, Wonnacott S. 6-Hydroxydopamine-induced apoptosis is mediated via extracellular autooxidation and caspase 3-dependent activation of protein kinase $\mathrm{C} \delta$. J. Biol. Chem., 281, 5373-5382 (2006).

21) Tarozzi A, Morroni F, Merlicco A, Hrelia S, Angeloni C, CantelliForti G, Hrelia P. Sulforaphane as an inducer of glutathione prevents oxidative stress-induced cell death in a dopaminergic-like neuroblastoma cell line. J. Neurochem., 111, 1161-1171 (2009).
22) Yan M, Huo Y, Yin S, Hu H. Mechanisms of acetaminophen-induced liver injury and its implications for therapeutic interventions. Redox Biol., 17, 274-283 (2018).

23) Du K, Ramachandran A, Jaeschke H. Oxidative stress during acetaminophen hepatotoxicity: sources, pathophysiological role and therapeutic potential. Redox Biol., 10, 148-156 (2016)

24) McGill MR, Yan H-M, Ramachandran A, Murray GJ, Rollins DE, Jaeschke H. HepaRG cells: A human model to study mechanisms of acetaminophen hepatotoxicity. Hepatology, 53, 974-982 (2011).

25) Yan H-M, Ramachandran A, Bajt ML, Lemasters JJ, Jaeschke H. The oxygen tension modulates acetaminophen-induced mitochondrial oxidant stress and cell injury in cultured hepatocytes. Toxicol. Sci., 117, 515-523 (2010).

26) Ferret PJ, Hammoud R, Tulliez M, Tran A, Trebeden H, Jaffray P, Malassagne B, Calmus Y, Weill B, Batteux F. Detoxification of reactive oxygen species by a nonpeptidyl mimic of superoxide dismutase cures acetaminophen-induced acute liver failure in the mouse. Hepatology, 33, 1173-1180 (2001).

27) Cabral H, Miyata K, Osada K, Kataoka K. Block copolymer micelles in nanomedicine applications. Chem. Rev., 118, 6844-6892 (2018).

28) Naruta $Y$, Maruyama K. High oxygen-evolving activity of rigidly linked manganese(III) porphyrin dimers. A functional model of manganese catalase. J. Am. Chem. Soc., 113, 3595-3596 (1991).

29) Patel M, Day BJ. Metalloporphyrin class of therapeutic catalytic antioxidants. Trends Pharmacol. Sci., 20, 359-364 (1999).

30) Li BQ, Dong X, Li N, Gao JY, Yuan Q, Fang SH, Gong XC, Wang SJ, Wang FS. In vitro enzyme-mimic activity and in vivo therapeutic potential of HSJ-0017, a novel Mn porphyrin-based antioxidant enzyme mimic. Exp. Biol. Med. (Maywood), 239, 1366-1379 (2014). 